\title{
CCR5 HIV-1 RECEPTOR PREDOMINANCE IN ADULT MALE PREPUCE; THE MAJOR ENTRY ROUTE FOR HIV-1 IN INDIGENOUS BLACK MALES IN ZAMBIA?
}

\author{
Mukape Mukape, Elliot Bufuku Kafumukache, Kaile Trevor
}

Correspondence to Mukape Mukape, University of Zambia, School of Medicine, Department of Anatomy, P.O.BOX 50110, Lusaka, Zambia. Telephone number +260 961915814, Email address: mukapemukape@gmail.com.

\section{ABSTRACT}

HIV-1 entry requires not only CD4 molecule but also CCR5 (CD 195) and CXCR4 (CD 184) coreceptors. A number of randomised controlled trials in Africa have reported that male circumcision (MC) reduces the risk of HIV-1 acquisition by up to $60 \%$. Other studies have reported that sexually transmitted infections (STIs) increase the risk of infection by HIV via an inflammatory recruitment of more HIV target cells to the foreskin. Our aim was to compare the density of HIV-1 co-receptors (CCR5 and CXCR4) in naïve penile prepuce of neonates and penile prepuce of adults with and without history of ulcerative STIs at Male Circumcision Centres in Lusaka, Zambia. Twenty (20) fresh foreskin samples were included: five (5) from neonates, ten (10) from adult males without history of ulcerative STIs and five (5) from adult males with a history of ulcerative STIs. Immediately following $M C$, fresh foreskin specimens were fixed using $10 \%$ normal buffered formalin and transported to University Teaching Hospital (UTH) where tissues were processed and stained with anti-CD 195 and anti-CD 184 antibodies. Neonatal penile foreskin co-receptor mean density for CCR5 and CXCR4 was $13 \pm 5.148 / \mathrm{mm}^{2}$ and $7 \pm 1.581 / \mathrm{mm}^{2}$ respectively. CCR5 mean density of adults without past history of ulcerative STIs was $42.1 \pm 11.874 / \mathrm{mm}^{2}$ while those with history of ulcerative STIs was $78.6 \pm 13.520 / \mathrm{mm}^{2}$. Densities of CCR5 were all statistically significant with both having Pvalue of 0.000 . CXCR4 mean density was $18.6 \pm 4.812 / \mathrm{mm}^{2}$ in adults without past history of ulcerative STIs and $23.4 \pm 4.393 / \mathrm{mm}^{2}$ in those with history of ulcerative STIs giving an insignificant P-value of 0.084 . It could be concluded that CCR5 co-receptors provide major entry route for HIV-1 in male adults and that CCR5 seemed to be mobilized more than CXCR4 to the prepuce during inflammation. This supports evidence that MC reduces CCR5 co-receptors for acquisition and transmission of R5 strains of HIV-1.

Key words: HIV, CCR5, CD 195, CD 184.

\section{INTRODUCTION}

HIV/AIDS is a global pandemic. As of 2016, approximately 36.7 million people were living with HIV globally of which $53 \%$ (19.4 million) were in Eastern and Southern Africa representing the hardest hit area (UNAIDS Fact Sheet, 2017).

A number of randomised controlled trials in Africa and other countries have reported that male circumcision (MC) reduces the risk of HIV-1 acquisition and transmission (Maibvise et al., 2014; McCoombe et al., 2006; Parana et al., 2014; Szabo et al., 2000; Weiss et al,
2011). The World Health Organization (WHO) actually report that this reduction is by up to $60 \%$ (UNAIDS/WHO, 2007). Other studies (Anderson et al., 2011; Dickerson et al, 1996; Jeanne et al., 2007) have reported that sexually transmitted infections (STIs) increase the risk of acquisition and infection of HIV by an inflammatory recruitment of more HIV target cells to the foreskin.

A lot of research has been done on how HIV enters into host cells (Bernard et al., 1984; Gao et al, 1999; Sousa et al., 2016). These 
cells include $\mathrm{T}$ helper cells, dendritic cells (DCs), macrophages and monocytes. The studies have revealed that these cells have the cluster of differentiation 4 (CD4) receptor molecules on their cell membranes and it is this unique molecule that is required for entry by the HIV virus.

However, binding of the HIV-1 virus to the CD4 receptor on host cells alone is not sufficient for entry/infection. Molecules called co-receptors are also needed to act as doors and allow the HIV virus to enter the host cell. The most important co-receptors for HIV virus entry are the beta-chemokine $\mathrm{C}-\mathrm{C}$ motif receptor 5 (CCR5) and the alpha-chemokine C-X-C motif receptor 4 (CXCR4) (Moriuchi et al., 1997).

The CCR5 receptor is the principal co-receptor for the R5 strains of HIV whereas the X4 strains of HIV-1 exploit the CXCR4 receptor (Dragic et al., 1996). These R5-dependent viruses are the strains predominantly responsible for the majority of the sexually transmitted HIV-1 harboured within macrophages, dendritic cells, and activated or memory $T$ cells whereas the $\mathrm{X} 4$ strains are responsible primarily for disease progression and, less frequently, primary transmission.
Most of the studies that recommend male circumcision (MC) as a protective means against heterosexual HIV acquisition, transmission and infection are based on metaanalysis of epidemiologic studies and not on adequate laboratory scientific data. Very few studies (Jiang et al., 2015; Liu et al., 2016; Mc Coombe et al., 2006) in selected regions of the world have looked and reported on HIV receptor distribution and density in the epithelia tissue that come in first contact with the HIV virus.

Furthermore, contrasting results have been reported depending on geographical location where the study was carried out. Thus, additional similar studies have been recommended to be done from different ethnic and geographic populations to address this issue as they suggest the results could be affected by factors such as race, ethnicity and age.

No studies have been done in Zambia to support increased predisposition to HIV infection upon contracting ulcerative STIs in males. We compared the density of HIV-1 coreceptors (CCR5 and CXCR4) in the penile prepuce of neonates and adults with and without history of ulcerative STIs at Male Circumcision Centres in Lusaka, Zambia.

\section{METHODOLOGY}

The study was carried out at designated male circumcision centres in Lusaka district of Zambia.

Twenty indigenous black male neonates and adults above the age of 18 years with and without history of ulcerative STIs coming for elective male circumcision were included based on the non-probability sampling method. This consisted of foreskins from 5 male neonates, 10 adult males without history of ulcerative STIs and 5 adult males with history of ulcerative STIs. Similar smaller sample sizes have been used in other past immunohistochemistry studies (Kaile et al., 2015; McCoombe et al., 2006; Paydas et al., 2004).
The study compared the density of HIV-1 coreceptors in the prepuce of neonates and adult males with or without a history of ulcerative STIs. A short questionnaire was administered to determine the social demographic variables and the reasons for circumcision. Adults were further asked if they had a history of contracting ulcerative STIs and whether they received treatment. To ensure validity and reliability, the same interview schedule and method of collecting and processing specimens and data was used for all study participants.

The data collected was entered and stored into the data editor of IBM $^{\circledR}$ SPSS $^{\circledR}$ and statistically analysed using IBM SPSS Statistics for Windows Version 20.0 (IBM Corp. Armonk, 
NY, USA). Ethical clearance was obtained from the University of Zambia Biomedical
Research Ethics Committee (UNZABREC).

\section{RESULTS}

A total of 20 participants who met the inclusion criteria consented and were recruited to the study. Their overall demographic and laboratory results are shown in Table 1. Most abundant HIV-1 co-receptors in the penile prepuce of a participant are the
CD 195 compared to the CD 184 and that the densities for these two types of co-receptors are higher in adults with past history of ulcerative STIs than those without history of ulcerative STIs.

Table 1: Overall Results of Participants Recruited

\begin{tabular}{|c|c|c|}
\hline Age & $\begin{array}{l}\text { Number of CD } 195 \\
\text { Receptors/mm² }\end{array}$ & $\begin{array}{l}\text { Number of CD } 184 \\
\text { Receptors } / \mathrm{mm}^{2}\end{array}$ \\
\hline \multicolumn{3}{|c|}{ Neonates } \\
\hline 15 days & 19 & 8 \\
\hline 19 days & 8 & 6 \\
\hline 20 days & 18 & 7 \\
\hline 22 days & 11 & 9 \\
\hline 25 days & 9 & 5 \\
\hline \multicolumn{3}{|c|}{ Adults with STIs } \\
\hline 16 yrs & 90 & 30 \\
\hline 18 yrs & 88 & 20 \\
\hline 19 yrs & 80 & 23 \\
\hline 20 yrs & 79 & 25 \\
\hline 21 yrs & 56 & 19 \\
\hline \multicolumn{3}{|c|}{ Adults without STIs } \\
\hline 18 yrs & 32 & 18 \\
\hline 19 yrs & 35 & 13 \\
\hline 20 yrs & 62 & 24 \\
\hline 21 yrs & 43 & 17 \\
\hline 22 yrs & 30 & 13 \\
\hline 22 yrs & 40 & 14 \\
\hline 23 yrs & 49 & 26 \\
\hline 26 yrs & 55 & 23 \\
\hline 25 yrs & 25 & 22 \\
\hline 26 yrs & 50 & 16 \\
\hline
\end{tabular}




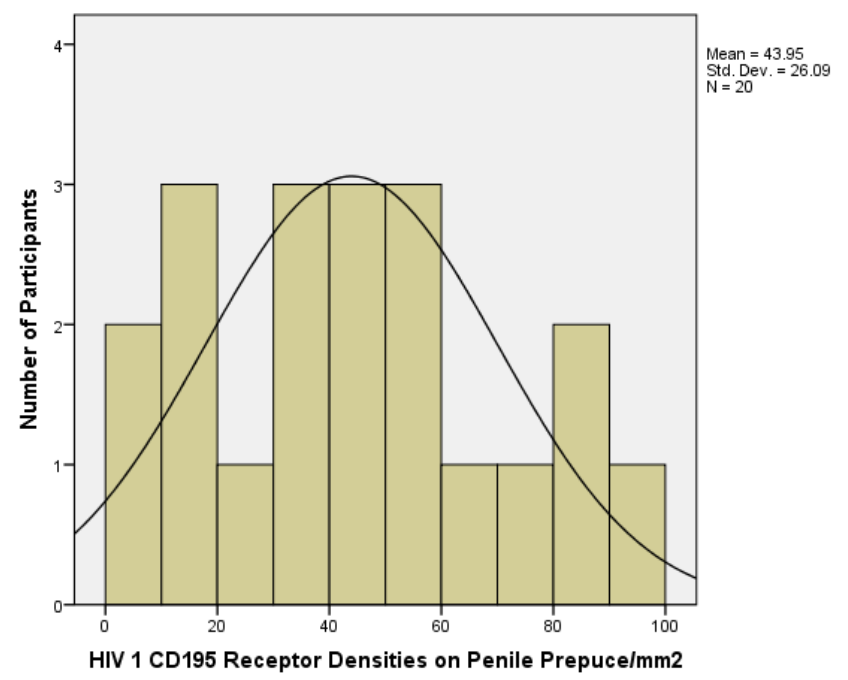

Figure 1: Frequency of HIV-1 CD 195 Co-receptor on Penile Prepuce. The average (mean) HIV-1 CD 195 receptor density was $43.95 \pm 26.09 / \mathrm{mm}^{2}$ for all the 20 participants.

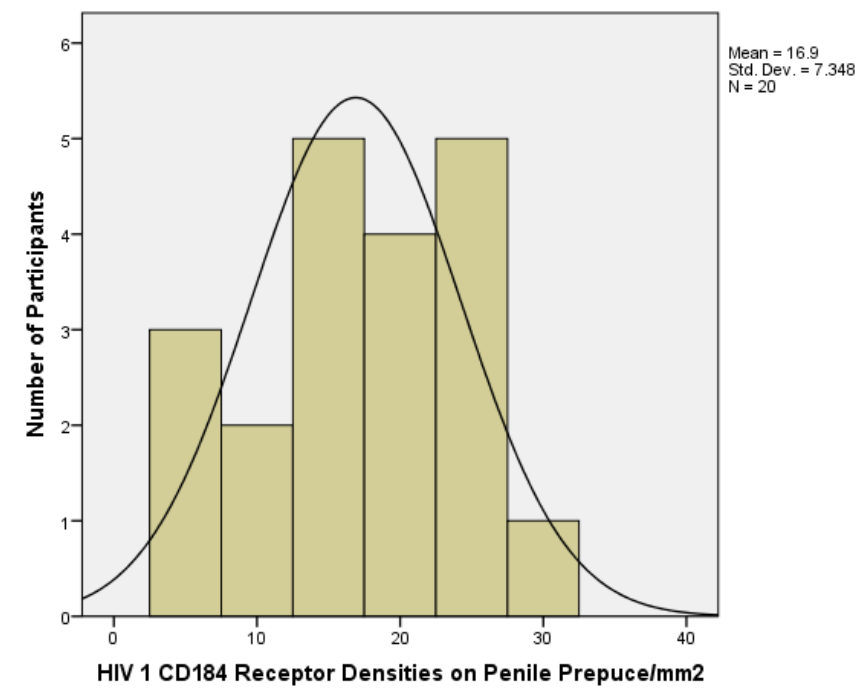

Figure 2: Frequency of HIV-1 CD 184 Co-receptor on Penile Prepuce. The average (mean) HIV-1 CD 184 receptor density was $16.9 \pm 7.348 / \mathrm{mm}^{2}$ for all the 20 participants.

The mean (average) CD 195 density in neonates was $13 \pm 5.148 / \mathrm{mm}^{2}$ (Table 2). For adults without past history of ulcerative STIs, the CD 195 mean density was $42.1 \pm 11.874 / \mathrm{mm}^{2}$. The calculated P-value was 0.000 which was statistically significant with a confidence interval of $95 \%$. This analysis indicates that the CD 195 co-receptor density in the penile prepuce was three (3) times higher in adults without past history of ulcerative STIs than in neonates.

The mean (average) CD 195 density in neonates was $13 \pm 5.148 / \mathrm{mm}^{2}$ (Table 3 ). For adults with past ulcerative STIs, the CD 195 mean density was $78.6 \pm 13.520 / \mathrm{mm}^{2}$. The calculated P-value was 0.000 which was statistically significant with a confidence interval of $95 \%$. This analysis indicates that the CD 195 co-receptor density in the penile prepuce was six (6) times higher in adults with past history of ulcerative STIs than in neonates.

The mean (average) CD 195 density in adults without history of ulcerative STIs was $42.1 \pm 11.874 / \mathrm{mm}^{2}$ (Table 4). For adults with past ulcerative STIs, the CD 195 mean density was $78.6 \pm 13.520 / \mathrm{mm}^{2}$. The calculated $P$ value was 0.000 which was statistically 
significant with a confidence interval of $95 \%$. This analysis indicates that the CD 195 coreceptor density in the penile prepuce was almost two (2) times higher in adults with past history of ulcerative STIs than in adults without past history of ulcerative STIs.

The mean (average) CD 184 density in neonates was $7 \pm 1.581 / \mathrm{mm}^{2}$ (Table 5). For adults without past history of ulcerative STIs, the $C D \quad 184$ mean density was $18.6 \pm 4.812 / \mathrm{mm}^{2}$. The calculated P-value was 0.000 which was statistically significant with a confidence interval of $95 \%$. This analysis indicates that the CD 184 co-receptor density in the penile prepuce was almost three (3) times higher in adults without past history of ulcerative STIs than in neonates.

The mean (average) CD 184 density in neonates was $7 \pm 1.581 / \mathrm{mm}^{2}$ (Table 6). For adults with past ulcerative STIs, the CD 184 mean density was $23.4 \pm 4.393 / \mathrm{mm}^{2}$. The calculated P-value was 0.000 which was statistically significant with a confidence interval of $95 \%$. This analysis indicates that the CD 195 co-receptor density in the penile prepuce was almost three (3) times higher in adults with past history of ulcerative STIs than in neonates. The mean (average) CD 184 density in adults without history of ulcerative STIs was $18.6 \pm 4.812 / \mathrm{mm}^{2}$ (Table 7). For adults with past ulcerative STIs, the CD 184 mean density was $23.4 \pm 4.393 / \mathrm{mm}^{2}$. The calculated P-value was 0.084 which was not statistically significant. The results showed that there was no statistical difference in the CD 184 co-receptor density in the penile prepuce of adults with past history of ulcerative STIs and adults without past history of ulcerative STIs suggesting no marked mobilization of CXCR4 during ulcerative inflammatory response.

Table 2: Relationship of CD195 Receptor Density in Neonates vs Adults without STIs

\begin{tabular}{|l|l|l|l|l|c|}
\hline & Age & N & Mean & SD & P-Value \\
\hline $\begin{array}{l}\text { CD195 receptor } \\
\text { densities }\end{array}$ & Neonates & 5 & 13.00 & 5.148 & 0.000 \\
\cline { 2 - 5 } $\mathrm{mm}^{2}$ ) & Adults without past STIs & 10 & 42.10 & 11.874 & \\
\hline
\end{tabular}

Table 3: Relationship of CD195 Receptor Density in Neonates vs Adults with STIs

\begin{tabular}{|l|l|l|l|r|r|}
\hline & Age & N & Mean & \multicolumn{1}{l|}{ SD } & P-Value \\
\hline $\begin{array}{l}\text { CD195 receptor } \\
\text { densities (per } \\
\mathrm{mm}^{2} \text { ) }\end{array}$ & Neonates & 5 & 13.00 & 5.148 & 0.000 \\
\cline { 2 - 5 } & Adults with STIs & 5 & 78.60 & 13.520 & \\
\hline
\end{tabular}

Table 4: Relationship between CD195 (CCR5) Receptor Density and STI status

\begin{tabular}{|lr|l|l|l|l|c|}
\hline & Participants STI status & N & Mean & SD & P-Value \\
\hline $\begin{array}{l}\text { CD195 receptor } \\
\text { densities }\end{array}$ & Negative & 10 & 42.10 & 11.874 & 0.000 \\
\cline { 2 - 6 } $\mathrm{mm}^{2}$ ) & Per & 5 & 78.60 & 13.520 & \\
\hline
\end{tabular}

Table 5: Relationship between CD184 Receptor Density in Neonates vs Adults without STIs

\begin{tabular}{|c|c|c|c|c|c|}
\hline 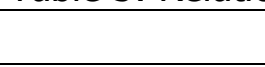 & Participants age & $\mathbf{N}$ & Mean & Standard deviation & P-Value \\
\hline \multirow{2}{*}{$\begin{array}{l}\text { CD184 } \\
\text { receptor } \\
\text { densities (per } \\
\mathrm{mm}^{2} \text { ) }\end{array}$} & Neonates & 5 & 7.00 & 1.581 & \multirow[t]{2}{*}{0.000} \\
\hline & Adults without STIs & 10 & 18.60 & 4.812 & \\
\hline
\end{tabular}


Anatomy Journal of Africa. 2018. Vol 7 (2): 1182 - 1191.

Table 6: Relationship of CD184 Receptor Density in Neonates vs Adults with STIs

\begin{tabular}{|l|l|l|l|l|c|}
\hline & Age & N & Mean & SD & P-Value \\
\hline $\begin{array}{l}\text { CD184 receptor } \\
\text { densities (per } \mathrm{mm}^{2} \text { ) }\end{array}$ & Neonates & 5 & 7.00 & 1.581 & 0.000 \\
\cline { 2 - 5 } & Adults with STIs & 5 & 23.40 & 4.393 & \\
\hline
\end{tabular}

Table 7: Relationship between CD184 Receptor Density and STI status

\begin{tabular}{|l|l|l|l|c|c|}
\hline & Participants STI status & $\mathbf{N}$ & Mean & Standard deviation & P-Value \\
\hline \multirow{2}{*}{$\begin{array}{l}\text { CD184 receptor } \\
\text { densities (per } \mathrm{mm}^{2} \text { ) }\end{array}$} & Negative & 10 & 18.60 & 4.812 & 0.084 \\
\cline { 2 - 6 } & Positive & 5 & 23.40 & 4.393 & \\
\hline
\end{tabular}

\section{DISCUSSION}

Our current study showed that the frequency of CD 195 and CD 184 on the penile prepuce was not the same regardless of age and history of previous ulcerative sexually transmitted infections (STIs).

For all the 20 participants, the CD 195 mean density was found to be $43.95 \pm 26.09 / \mathrm{mm}^{2}$ while that of CD 184 the mean density was $16.9 \pm 7.348 / \mathrm{mm}^{2}$. This demonstrated that CD 195 co-receptors are the most abundant compared to CD 184 co-receptors in the penile prepuce. This could suggest that most strains of HIV-1 enter cells using the CD 195 co-receptor.

These findings are consistent with the results of a study done in Australia by McCoombe et al, 2006, who in their study of potential HIV-1 target cells in the human penis found that the mean densities of CCR5 (CD 195) and CXCR4 (CD 184) in the outer foreskin were $33 / \mathrm{mm}^{2}$ and $12 / \mathrm{mm}^{2}$ respectively. The inner foreskin mean densities were found to be $28 / \mathrm{mm}^{2}$ for CD 195 co-receptor and 2/mm² for CD 184 co-receptor.

Although the actual co-receptor densities differ between this study and that of McCoombe et al, 2006, they both demonstrate that CCR5 co-receptors are the most abundant compared to the CXCR4 coreceptors on the male prepuce.
Other studies also showed that the foreskin immune cells express predominantly CCR5 HIV-1 co-receptors (Patterson et al., 2002; Wright et al., 2011).

From our study, the age of the participant had an influence on the density of both CD 195 and CD 184 co-receptors on the penile prepuce in a significant manner.

The mean density of CD 195 in neonates was found to be $13 \pm 5.148 / \mathrm{mm}^{2}$. Comparing the CD 195 mean density in neonates with that of adults without past history of ulcerative STIs which was found to be $42.1 \pm 11.874 / \mathrm{mm}^{2}$, the calculated P-value was 0.000 which was statistically significant with a confidence interval of $95 \%$. This analysis indicated that the CD 195 co-receptor density in the penile prepuce was three (3) times higher in adults without past history of ulcerative STIs than in neonates.

For adults with past ulcerative STIs, the CD 195 mean density was $78.6 \pm 13.520 / \mathrm{mm}^{2}$. Comparing this with the CD 195 mean density found in neonates, the calculated P-value was 0.000 which was statistically significant with a confidence interval of $95 \%$. This analysis indicated that the CD 195 co-receptor density in the penile prepuce was six (6) times higher in adults with past history of ulcerative STIs than in neonates suggesting an increased mobilization during inflammation. 
A similar pattern of density of CD 184 in neonates versus adults was found to be the same as that of CD 195. The CD 184 coreceptor density in the penile prepuce was higher in adults with and without past history of ulcerative STIs than in neonates.

The mean CD 184 density in adults without history of ulcerative STIs was $18.6 \pm 4.812 / \mathrm{mm}^{2}$ while that of adults with history of ulcerative STIs was $23.4 \pm 4.393 / \mathrm{mm}^{2}$. For the neonates the CD 184 mean density was found to be $7 \pm 1.581 / \mathrm{mm}^{2}$. When the CD 184 mean densities for both neonates versus adults without history of ulcerative STIs and neonates versus adults with history of ulcerative STIs were compared, the calculated $P$-value for both categories was found to be 0.000 which was statistically significant with a confidence interval of $95 \%$. However, there was no significant increase of CXCR4 coreceptors on past inflammatory ulcerative STI foreskin.

The study shows that neonates have a lower HIV-1 co-receptor density than adults. This could be attributed to the fact that the neonatal foreskin is less subjected to a number of inflammatory responses. Various studies (Anderson et al, 2011; Fleming et al, 1999; Hirbod et al, 2014) report that attrition forces on the foreskin or ulcerative STIs can cause abrasions, tears or ulcers on the foreskin which cause inflammation, bringing more HIV-1 high affinity target cells to the foreskin and later lead to greater risk for acquisition, infection and transmission of HIV.

Circumcision therefore may decrease HIV-1 infection. This is possibly due to the reduction of potential target cells as well as an inflamed environment that recruits possible HIV-1 high affinity target cells to the foreskin (Maibvise et al, 2014; McCoombe et al, 2006; Parana et al, 2014; Szabo et al., 2000; Weiss et al., 2000).

Uncircumcised adolescents and those in early twenties are thus at a greater risk of acquisition and infection of HIV. This is because many young men are involved in sexual debut and engagement in high risky sexual behaviour such as multiple sexual partners, having sex while under the influence of drugs or alcohol and having unprotected sexual intercourse (Shisana et al, 2014).

Our study further showed that past history of ulcerative STIs had a greater impact on the density of CD 195 and not the CD 184 coreceptors on the penile prepuce.

The mean CD 195 density in adults without history of ulcerative STIs was found to be $42.1 \pm 11.874 / \mathrm{mm}^{2}$. For adults with past ulcerative STIs, the CD 195 mean density was $78.6 \pm 13.520 / \mathrm{mm}^{2}$. The calculated P-value was 0.000 which was statistically significant with a confidence interval of $95 \%$. This analysis indicated that the CD 195 co-receptor density in the penile prepuce was almost double in adults with past history of ulcerative STIs than in adults without past history of ulcerative STIs.

When the mean density of CD 184 was analysed, it was found that the CD 184 coreceptor density in the penile prepuce was slightly higher in adults with past history of ulcerative STIs than in adults without past history of ulcerative STIs. The mean CD 184 density in adults without history of ulcerative STIs was found to be $18.6 \pm 4.812 / \mathrm{mm}^{2}$ while that of adults with past ulcerative STIs, the CD 184 mean density was $23.4 \pm 4.393 / \mathrm{mm}^{2}$. The calculated P-value was found to be 0.084 which was not statistically significant. This indicates that the history of an ulcerative STI on the foreskin may not increase the expression of CXCR4 co-receptors significantly. This explanation is supported by some studies that have reported that certain STIs like Treponema pallidum or bacterial lipopolysaccharides can down-regulate CXCR4 expression on monocytes in an in vitro model and in a human skin blister fluid system (Sampson et al., 1996; Sellati et al., 2000).

The findings of this study on the expression of HIV-1 co-receptors on the previously STI ulcerated foreskin is consistent with a study done by Jeanne et al, 2007, examined the expression of HIV-1 co-receptors (CCR5 and CXCR4) by monocytic cells within human genital ulcers. The research concluded that monocytes recruited to genital ulcer disease (GUD) sites express increased levels of CCR5. This increased expression could account, at 
least in part, for enhanced HIV-1 transmission in the setting of GUD.

Further, the fact that this study showed that individuals who had past history of ulcerative STIs have a higher density of HIV-1 coreceptors on their penile prepuce than those who never had such a history therefore means that uncircumcised individuals with history of ulcerative STIs maybe more susceptible to acquisition and infection of HIV1 via the penile prepuce than uncircumcised individuals without history of ulcerative STIs.

These findings are supported by various past studies. A study done by Anderson et al., (2011), reviewed and discussed the potential mechanisms underlying the circumcision effect and re-examined the assumption that the foreskin is the principle penile HIV infection site. They concluded that ulcerative STIs increase the susceptibility to HIV acquisition by eroding the protective epithelial layer and by attracting and activating HIV target cells in the epithelium. Another study by Cameron et al, 1989, showed that the acquisition of HIV was highly associated with having genitourinary ulcerative disease (GUD), being uncircumcised, and having frequent contact with sex workers. In their study, men who reported a single contact with sex workers, and who had seroconverted, all had genital ulcers. Galvin and Cohen, 2004, in their extensive review demonstrated that persons with STIs that cause ulcers and inflammation are more vulnerable to HIV than healthy individuals. According to Fleming et al, (1999), the adjusted risk ratio for HIV acquisition and infection for a person with GUD ranges from 2.2 to 11.3 , whereas with non-ulcerative STIs it is 3-4. Dickerson et al, 1996, reported that associations of ulcerative STIs versus HIV acquisition and infection persisted in most cases even after adjusting for sexual behaviour and other confounding factors.

This research therefore concludes that the foreskin with a previous ulcerative STI had significant presence of CCR5 co-receptors than CXCR4 co-receptors and hence HIV-1 infection could more likely be acquired and transmitted by the R5-dependent (M-tropic) strains of HIV-1 than X4-dependent (T-cell tropic) strains of HIV-1. The beta-chemokine receptor CCR5 is the principal co-receptor for the R5 strains of HIV whereas the X4 strains of HIV-1 exploit the a-chemokine receptor CXCR4 (Dragic et al, 1996). Despite male circumcision been done in Zambia, no work on the density of HIV-1 co-receptors in the penile prepuce of neonates and adults using immunohistochemistry has been published. Hence, the strength of our study is that it is an insightful study that could be used as a baseline study for future works in Zambia.

The immunohistochemistry reagents were very expensive and the finances for the research were limited. This prevented recruiting a very big sample size of participants. Furthermore, this limitation hindered the study from looking at not only the HIV-1 co-receptor density but also the distribution of these receptors in the foreskins.

However, from our research findings, we recommend more robust campaign measures by the authorities in Zambia (e.g. Ministry of Health, Non-Governmental Organizations like Centre for Infectious Disease Research in Zambia) for more men to undergo male circumcision. These measures can be integrated heavily with other reproductive health services.

In conclusion, we concluded that both CCR5 and CXCR4 HIV-1 co-receptor density was found to be higher in adults compared to neonates. The CCR5 co-receptor density was almost two-fold while that of CXCR4 had an insignificant difference in adults with past history of ulcerative STIs compared to those without history of ulcerative STIs. CCR5 coreceptors were found to be more abundant than the CXCR4 co-receptors in the penile prepuce regardless of age and previous STI status. Since the CCR5 co-receptors were the most abundant, they could be the major entry route for HIV-1 in indigenous black males in Zambia. Furthermore, uncircumcised individuals with history of ulcerative STIs could be more susceptible to acquisition, infection and transmission of the R5 strains of HIV-1 on the penile prepuce than 
ulcerative STIs.

ACKNOWLEDGEMENTS: The authors would like to thank the study participants and the research assistants for their cooperation and trust in this research. We further thank Professor Krikor Erzingatsian, Dr. Aaron Shibemba and Dr. Peter Julius for their technical support and allowing us to conduct our research in their Immunohistochemistry Laboratory. We remain deeply indented to the University of Zambia through the Staff Development Office (SDO) and School of Medicine for the financial support rendered to us in sponsoring this study.

COMPETING INTERESTS: The authors declare no conflict of interest.

\section{REFERENCES}

1. Anderson D, Politch JA, Pudney J. 2011. HIV infection and immune defense of the penis. Am J Reprod Immunol; 65: 220-229

2. Bernard AR, Boumsell L, Dausset J, Milstein C, Schlossmann SF, eds. 1984. Leucocyte typing: human leucocyte differentiation antigens detected by monoclonal antibodies. Springer, Berlin Springer, 45-48.

3. Cameron DW, Simonsen JN, D'Costa $D$, Ronald AR, Maitha GM, Gakinya MN, Cheang M, Ndinya-Achola JO, Piot P, Brunham RC, et al. Lancet. (August, 1989). 2 (8660):403-7.

4. Dickerson MC, Johnston J, Delea TE, White A, Andrews E. 1996. The causal role for genital ulcer disease as a risk factor for transmission of human immunodeficiency virus an application of the Bradford Hill criteria. Sex Transm Dis. 23(5): 429-40.

5. Dragic T, Litwin V, Allaway GP, Martin SR, Huang Y, Nagashima KA, Cayanan C, Maddon PJ, Koup RA, Moore JP, Paxton WA. 1996. HIV-1 entry into CD4 cells is mediated by the chemokine receptor CC-CXR-5. Nature, 381:667-73

6. Fleming DT, Wasserheit JN. 1999. From epidemiological synergy to public health policy and practice the contribution of other sexually transmitted diseases to sexual transmission of HIV infection. Sex Transmit Infect. 75(1): 3-17.

7. Galvin SR, Cohen MS. 2004. The role of sexually transmitted diseases in HIV transmission. Nat Rev Microbiol. 2(1): 33-42.

8. Gao F, Bailes E, Robertson DL, Chen Y, Rodenburg CM, Michael SF, Cummins LB, Arthur LO, Peeters M, Shaw GM, Sharp PM, Hahn BH. 1999. Origin of HIV-1 in the chimpanzee Pan troglodytes troglodytes, Macmillan Magazines Ltd, volume 397, 495-499.

9. Hirbod T, Kong X, Kigozi G, Ndyanabo A, Serwadda D, Prodger JL, et al. 2014 HIV Acquisition Is Associated with Increased Antimicrobial Peptides and Reduced HIV Neutralizing IgA in the Foreskin Prepuce of Uncircumcised Men. PLoS Pathog 10(10): e1004416. https://doi.org/10.1371/journal.ppat.1004416

10. Jeanne S. Sheffield, George D. Wendel, Donald D. McIntire, Michael V. 2007. Norgard; Effect of Genital Ulcer Disease on HIV-1 Coreceptor Expression in the Female Genital Tract, The Journal of Infectious Diseases, Volume 196, Issue 10, Pages 1509-1516.

11. Jiang J, Jinming $S$, Xiaobo $Y$, Mingbo $H$, Wei $D$, Jiegang $H$, Bingyu $L$, Bo $Q$, Halmurat $U$, Chaohui Z, Qianqiu W, Qian W, Yuhua R, Li Y, Hao L. 2015. Acceptability of Male Circumcision among College Students in Medical Universities in Western China: Plos One Journal,10 (9): e0135706

12. Kaile T, Simakando M, Korolova L, Malyangu E, Maswahu D. 2015. Expression of Ki-67 in BCell Non-Hodgkin's Lymphomas of Indigenous Black Zambians. Journal of Med Sc and Tech; 4(3): Page 228-234. 
13. Liu Y, Qian HZ, Ruan Y, Milam DF, Spiegel HM, Yin L, Li D, Shepherd BE, Shao Y, Vermund $\mathrm{SH}$. 2016. Lower HIV risk among circumcised men who have sex with men in China; AIDS Journal, vol 71, 444-451

14. Maibvise C, Mavundla TR. 2014. Reasons for the low uptake of adult male circumcision for the prevention of HIV transmission in Swaziland, African AIDS Journal, 13 (3): 281-9

15. McCoombe SG, Short RV. 2006. Potential HIV-1 target cells in the human penis. AIDS, 20(11): 1491-5.

16. Moriuchi M, Moriuchi $\mathrm{H}$, Turner W, Fauci AS. 1997. Cloning and analysis of the promoter region of CXCR4, a co-receptor for HIV-1 entry, Journal of Immunology, 159 (9) 4322-9.

17. Parana HMJ, William JHM, David M, John K, Andrew V, Stuart T. 2014. Male Circumcision and HIV Transmission; What Do We Know?; Open AIDS Journal, volume 8; 31-44

18. Patterson BK, Landay A, Siegel JN, Flener Z, Pessis D,Chaviano A, Bailey RC. 2002. Susceptibility to human immunodeficiency virus-1 infection of human foreskin and cervical tissue grown in explant culture. Am J Pathol, 161:867-873.

19. Paydas, S., Ergin, M., Tanriverdi, K., Yavuz, S., Disel, U., Kilic, N. B., Erdogan, S., Sahin, B., Tuncer, I. and Burgut, R. 2004. Detection of hepatitis C virus RNA in paraffin-embedded tissues from patients with non-Hodgkin's lymphoma. American journal of pathology, 76: 252-7

20. Sampson M, Libert F, Doranz BJ. 1996. Resistance to HIV-1 infection in Caucasian individuals bearing mutant alleles of the CCR-5 chemokine receptor gene. Nature 382:722-5

21. Sellati TH, Wilkinson DA, Sheffield JS, Koup RA, Radolf JD, Norgard MV. 2000. Virulent treponema pallidum, lipoprotein, and synthetic lipopeptides induce CCR5 on human monocytes and enhance their susceptibility to infection by human immunodeficiency virus type 1. J Infect Dis, 181:283-93.

22. Shisana, O, Rehle, T, Simbayi LC, Zuma, K, Jooste, S, Zungu N, Labadarios, D, Onoya, D.E.A. 2014. South African National HIV Prevalence, Incidence and Behaviour Survey, HSRC Press, p.194.

23. Sousa JD, Marina PT, Barry SH, Ricardo JC, Viktor M, Anne-Mieke V. 2016. Male Circumcision and the Epidemic of Emergence of HIV-2 in West Africa, PLos One 11 (12): e0166805.

24. Szabo R, Short RV. 2000. How does male circumcision protect against HIV infection? BMJ; 320:1592-1594.

25. UNAIDS/WHO 2007 28/03/ 2007. WHO and UNAIDS announce recommendations from expert meeting on male circumcision for HIV prevention Paris.

26. UNAIDS Fact Sheet- Latest global and regional statistics on the status of the AIDS epidemic, Worlds AIDS Day 2017.

27. Weiss HA, Quigley MA, Hayes RJ. 2000. Male circumcision and risk of HIV infection in subSaharan Africa: a systematic review and meta-analysis. AIDS; 14:2361-2370.

28. Wright E, Mugaba S, Grant P, Parkes-Ratanshi R, Van der Paal L, Grosskurth H, et al. 2011 Coreceptor and Cytokine Concentrations May Not Explain Differences in Disease Progression Observed in HIV-1 Clade A and D Infected Ugandans. PLoS ONE 6(5): e19902. https://doi.org/10.1371/journal.pone.0019902 